\title{
Estudo de infecções respiratórias agudas virais em crianças atendidas em um centro pediátrico em Salvador (BA)
}

\author{
Hospital study of acute respiratory infections in children of Northeast Brazil
}

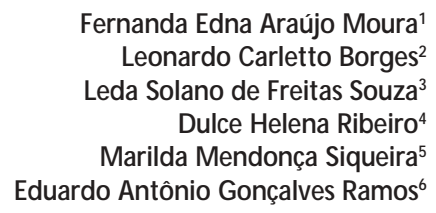

unitermos

Infecçōes respiratórias agudas

Crianças

Vírus

\section{resumo}

De janeiro a dezembro de 1998, foram analisados 482 casos de infecção respiratória aguda em crianças atendidas na emergência e nas enfermarias do Centro Pediátrico Professor Hosannah de Oliveira, da Universidade Federal da Bahia, em Salvador. O objetivo deste estudo é conhecer o papel dos vírus na etiologia destas infecções. Secreções nasofaríngeas foram examinadas para deteç̧ão viral por imunofluorescência e cultura celular. Vírus foram detectados em 154 casos (31,9\%). O vírus sincicial respiratório (VSR) foi o mais prevalente $(55,2 \%)$, seguido pelos vírus influenza $A(17,5 \%)$ e parainfluenza $3(16,2 \%)$, adenovírus $(7,1 \%)$, influenza B $(3,8 \%)$ e parainfluenza $1(0,64 \%)$. $O$ período epidêmico de VSR foi relacionado à estação de chuvas. Um surto de influenza foi observado nos meses de setembro a novembro. A maioria das infecções foi representada por infecção de trato respiratório superior (63,3\%), enquanto que as infecções de trato respiratório inferior foram detectadas em 177 casos (36,7\%). Infecções respiratórias agudas virais foram mais freqüentes em crianças até um ano de idade $(72,7 \%)$.

\section{abstract}

From January to December 1998, 482 cases of acute respiratory infections in children attended at the emergence or pediatric wards of Centro Pediátrico Professor Hosannah de Oliveira, of Universidade Federal da Bahia, in Salvador (Brazil), were analysed. The aim of this study was to know data about the role of viruses in these infections. Nasopharyngeal secretions were examined for viruses by indirect immunofluorescence and cell culture. Viruses were detected in 154 (31.9\%) cases. Respiratory syncytial virus (RSV) was the most prevalent (55.2\%), followed by influenza A (17.5\%), parainfluenza 3 (16.2\%), adenoviruses (7.1\%), influenza B (3.8\%) and parainfluenza 1 (0.64\%). The epidemic period of RSV was related to the rainy season. One outbreak of influenza was observed from September to November. The majority of the infections were represented by upper respiratory tract infection (63.3\%) while lower respiratory tract infections were detected in 177 (36.7\%) cases. Viral acute respiratory infections were more frequent in children until one year of age (72.7\%). key words

Acute respiratory infections

Children

Viruses

\section{Introdução}

As infecções respiratórias agudas (IRAs) são causas importantes de morbidade e mortalidade infantil em todo o mundo, apresentando, no entanto, um maior impacto em países em desenvolvimento, onde as taxas de mortalidade infantil relacionadas a este problema são bem maiores $(6,16,18,21,28)$. No Brasil, as IRAs e as doen- ças diarréicas são as principais causas de mortalidade em crianças com menos de cinco anos de idade (23). Os vírus são considerados os agentes predominantes de IRA, seja como patógeno principal ou predispondo a infecções bacterianas secundárias, sendo responsáveis por 20\% a $30 \%$ dos casos que evoluem para o óbito $(4,5,25,30)$.
1. Doutora em Patologia pelo Curso de Pós-Craduação em Patologia da Universidade Federal da Bahia (UFBA/Fiocruz); médica; professora adjunta da disciplina de Microbiologia do Departamento de Patologia Medicina Legal da Universidade Federa do Ceará

2. Acadêmico de Medicina; bolsista de iniciação cientifica (CNPq) do Laboratório de Patologia e Doenças Virais do Centro de Pesquisa Conçalo Moniz, Fiocruz, Salvador-BA.

3. Doutora em Medicina; pediatra do Centro Pedíatrico Professor Hosannah de Oliveira (CPPHO), da UFBA. 4. Pediatra do CPPHO/UFBA. 5. Doutora em Ciências (Microbiologia); coordenadora do Laboratorio de Virus Respiratórios da Flocruz/Rio de aneiro. 6. Médico patologista; doutor em Patologia Pesquisas Conçalo Moniz, da Fiocruz/Salvado professor adjunto de Patologia da UFBA. Trabalho realizado no Laboratório de Patologia Doenças Virais do Centro de Pesquisas Conçalo Moniz, da Fiocruz/Salvador.

A Capes concedeu bolsa de doutorado à dra. Fernanda Edna Araújo Moura durante os quatro anos em que esteve afastada de suas atividades junto à Universidade Federal do Ceará. Estudo baseado na tese de doutorado em Patologia intitulada Infecçōes Respiratórias Aqudos Virais em Crianças de Salvador: Análise Antigênica e Cenômica dos Vírus Sincicial Respiratório e Adenovirus ssolados com Correlação Clínica, apresentada pela dra. Fernanda Edna Araúijo Moura e aprovada em 31 de julho de 2001 no Curso de Pós-Craduação da UFBA/Fiocruz. 
O diagnóstico das IRAs virais em países em desenvolvimento, como o Brasil, é feito comumente empregandose apenas critérios clínicos de anamnese e exame físico, análise de leucograma e imagens de radiografias de tórax. A utilização de testes laboratoriais diagnósticos específicos para agentes virais em caso de IRAs é limitada, devido a problemas financeiros e técnicos ou ainda devido ao fato de os vírus serem subestimados como agentes de infecções respiratórias que necessitam de hospitalização.

Estudos sobre IRAs virais em crianças brasileiras têm sido realizados, em sua maioria, em cidades das regiões Sudeste e Sul $(8,9,24,27,31,35,37,38,40)$. As informações semelhantes procedentes de outras regiões brasileiras ainda são escassas $(1,10,22,36)$. O objetivo deste estudo é relatar aspectos epidemiológicos, clínicos e virológicos de IRAs virais em crianças atendidas em um hospital de Salvador comparando-os com informações obtidas de estudos semelhantes realizados em outras regiões brasileiras.

\section{Materiais e métodos}

\section{Tipo e período de estudo}

O estudo caracteriza-se como descritivo, observacional, de corte transversal e demanda hospitalar, tendo sido realizado no período de janeiro a dezembro de 1998.

\section{População e local de estudo}

A população escolhida foi a de crianças com IRA, de ambos os sexos, com até cinco anos de idade e cujo início dos sintomas não tivesse ultrapassado sete dias. As crianças que participaram deste estudo foram atendidas nas enfermarias e na emergência do Centro Pediátrico Professor Hosannah de Oliveira da Universidade Federal da Bahia (CPPHO/UFBA). Este hospital está localizado numa região central de Salvador e atende predominantemente crianças de famílias de baixo nível socioeconômico de Salvador e cidades adjacentes.

\section{Coleta e registro de dados}

Dados demográficos, sociais e clínicos foram coletados numa ficha padrão pelo médico pesquisador ou pelo estudante de medicina engajado no estudo. As visitas hospitalares para coleta de amostras eram realizadas quatro vezes por semana. As informações sobre achados do exame físico e o diagnóstico estabelecido durante a consulta na emergência foram fornecidos pelo médico plantonista, ao pesquisador que coletava a amostra. A coleta da amostra e o preenchimento da ficha padrão eram feitos pelo médico que atendia às crianças nas enfermarias. 0 responsável por cada criança incluída no estudo era orientado sobre a coleta da amostra e o exame laboratorial que seria feito com a mesma. Um termo de consentimento para coleta das amostras foi obtido de todos os responsáveis pelos pacientes incluídos no estudo. O estudo foi aprovado pelos Comitês de Ética do CPPHO/UFBA e do Centro de Pesquisas Gonçalo Moniz, Fiocruz Bahia.

\section{Coleta e transporte da amostra}

Cerca de $1 \mathrm{ml}$ a $2 \mathrm{ml}$ de secreção nasofaríngea (SNF) foram obtidos por aspiração, segundo já descrito (11). As amostras foram transportadas para o Laboratório de Patologia e Doenças Virais do Centro de Pesquisa Gonçalo Moniz, Fiocruz de Salvador, em isopor com barras de gelo reciclável $\left(4^{\circ} \mathrm{C}\right)$.

\section{Processamento das amostras}

As amostras de SNF foram divididas em duas alíquotas: uma destinada ao isolamento viral em cultura de células e outra para realização da imunofluorescência indireta.

Imunofluorescência indireta (IFI) - Cada amostra era homogeneizada em tampão salina-fosfato (PBS) e centrifugada por 10 minutos a $1.000 \mathrm{~g}$. Três lâminas eram preparadas para cada amostra a ser analisada. Uma lâmina era utilizada para triagem dos casos positivos e negativos. Outra lâmina era utilizada para determinação do agente em casos positivos na triagem. Uma lâmina reserva era estocada em freezer a $-70^{\circ} \mathrm{C}$ para casos onde a repetição da IFI fosse necessária. Utilizou-se o Respiratory Panel 1 Viral Screening \& Identification Kit, da Chemicon, para pesquisa dos seguintes vírus: adenovírus, vírus sincicial respiratório (VSR), influenza A e B, parainfluenza 1, 2 e 3.

Cultura de células $(C C)$ - A outra alíquota de SNF era colocada em meio de transporte de vírus (meio essencial mínimo com sais de Earle suplementado com $1 \%$ de soroalbumina bovina, $500 \mathrm{U}$ de penicilina/ml; $50 \mathrm{ug}$ de gentamicina/ml e 2ug de anfotericina $\mathrm{B} / \mathrm{ml}$ ). Os procedimentos para isolamento viral foram realizados como descrito anteriormente (41). Células HEp-2 foram usadas para isolamento de VSR e adenovírus. Tubos com células HEp-2 que apresentassem efeitos citopáticos típicos da infecção por VSR ou adenovírus tinham suas monocamadas raspadas e as células eram submetidas a IFI para pesquisa de antígenos destes vírus.

Uma amostra era considerada positiva se algum dos vírus pesquisados fosse detectado pela IFI ou isolado em CC ou por ambas as técnicas. 


\section{Análise estatística}

A análise estatística descritiva foi realizada para todas as variáveis estudadas através de consulta a informações registradas em um banco de dados. A associação entre a presença dos diversos vírus pesquisados e os possíveis fatores de risco foi verificada através do teste de qui-quadrado de Pearson e do teste de Fisher. O nível de significância estatística de $5 \%$ foi utilizado para todos os testes.

\section{Resultados}

No ano de 1998 foram atendidas 3.273 crianças na emergência e 1.635 nas enfermarias do CPPHO/UFBA. Um total de 482 amostras de SNF foi coletado durante o período de estudo, em uma média mensal de 40 espécimes, sendo o máximo de 78 e o mínimo de seis amostras coletadas por mês. Um ou mais vírus foram identificados em 154 amostras. A taxa de prevalência de IRAs virais foi de 31,9\% (154/482). A ordem decrescente de freqüência dos vírus identificados foi a seguinte: VSR (54,5\%), influenza A (17,5\%), parainfluenza $3(16,2 \%)$, adenovírus (7,2\%), influenza B $(3,8 \%)$ e parainfluenza $1(0,6 \%)$.

A IFI e a CC foram positivas em 146 e 41 amostras, respectivamente. Um total de 30 VSR e 11 adenovírus foi isolado em cultura de células. Dos 30 VSR identificados por cultura de células, três não foram detectados através de IFI, o mesmo acontecendo com três adenovírus. Mais de um vírus foi identificado em seis amostras. Nestes casos as associações encontradas foram: VSR-parainfluenza 3, influenza A-parainfluenza 3 (dois casos); VSR-influenza A, adenovírus-parainfluenza 3, VSR-adenovírus.

A Figura apresenta a distribuição mensal de IRAs e dos vírus identificados nos casos positivos. As infecções de etiologia viral não foram distribuídas na mesma freqüên-

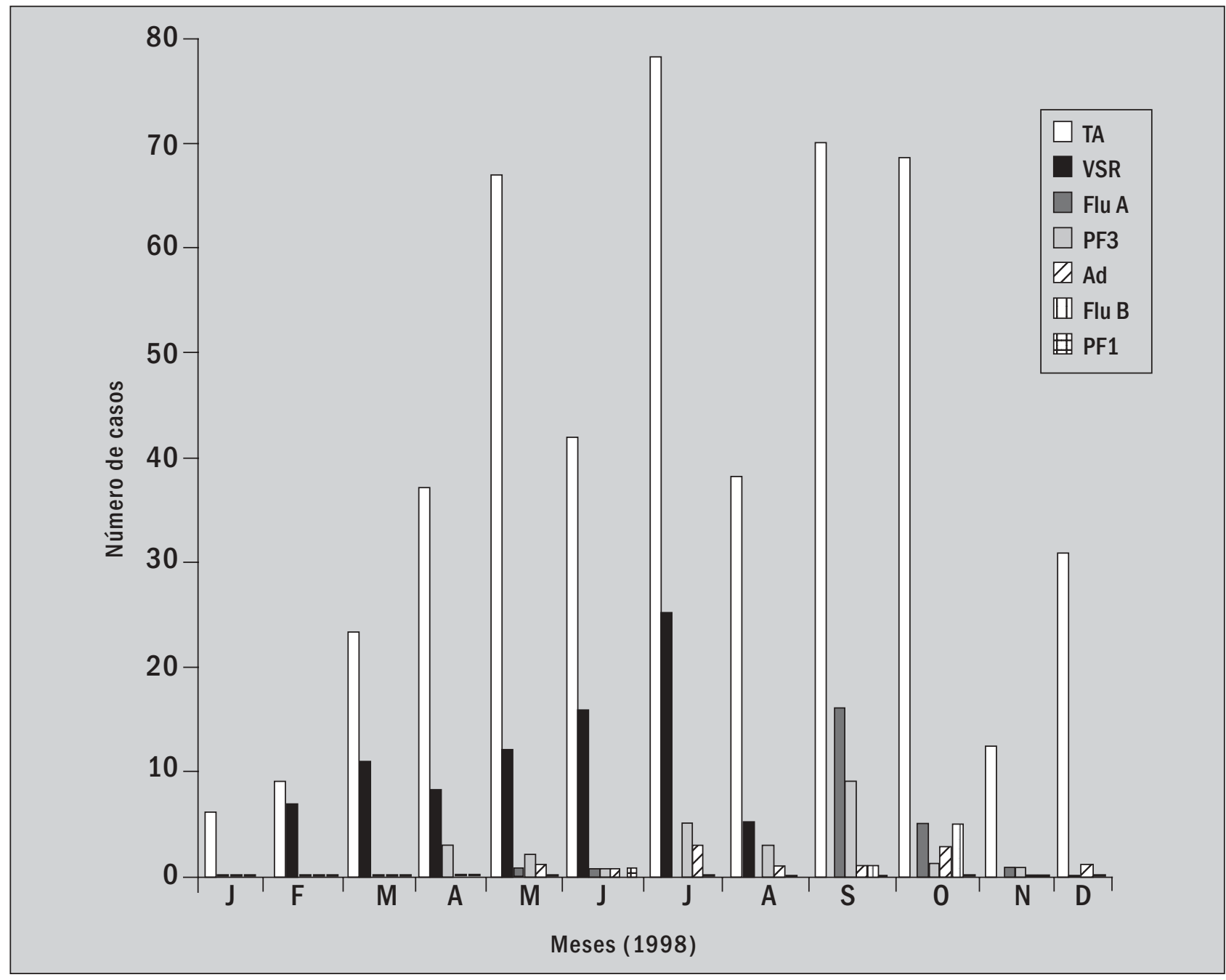

Figura - Distribuição mensal dos vírus identificados em 482 casos de infecção respiratória aguda em crianças atendidas no Centro Pediátrico Professor Hosannah de Oliveira, da Universidade Federal da Bahia, em Salvador, durante o período de janeiro a dezembro de 1998 (VSR = vírus sincicial respiratório; $A d=$ adenovírus; Flu $A=$ influenza A; Flu $B=$ influenza $B ; P F 1=$ parainfluenza 1; PF3 = parainfluenza $3 ; T A=$ total de amostras) 
cia durante o período de estudo, havendo uma maior ocorrência das mesmas no primeiro semestre do ano. O período epidêmico de VSR iniciou-se em fevereiro e prolongou-se até agosto, com um pico ocorrendo de março a julho, mostrando uma predileção pelo período de maior incidência de chuvas em Salvador. Um surto de influenza, com a maioria dos casos sendo devida ao vírus influenza A, foi observado nos meses de setembro a novembro. $\mathrm{O}$ adenovírus e o vírus parainfluenza 3 foram detectados em sete e oito meses, respectivamente. Apenas um caso de IRA pelo vírus parainfluenza 1 foi identificado. Nenhum caso foi associado ao vírus parainfluenza 2.

Algumas características das crianças incluídas no estudo podem ser vistas na Tabela 1. Não houve diferença significativa na ocorrência das IRAs virais segundo o sexo dos pacientes, embora um predomínio relativo tenha sido observado em crianças do sexo masculino (57\%).

A idade das crianças variou de três dias a quatro anos e nove meses. Entre as crianças com IRAs virais a idade variou de 12 dias a quatro anos. A maior ocorrência de IRA (67\%) e IRA viral $(72,7 \%)$ foi observada em crianças com até um ano de idade. O VSR foi o vírus mais freqüentemente identificado nestes casos $(76,2 \%)$, e, mais especificamente, entre os primeiros seis meses de vida (42,5\%). Apenas $7,4 \%$ das crianças tinham mais de dois anos de idade.

A maioria das amostras foi coletada de pacientes de emergência (74,7\%), sendo observada uma predominância estatisticamente significativa de casos positivos para vírus em pacientes atendidos neste setor $(p=0,024)$.

A relação entre síndromes clínicas e os vírus identificados pode ser observada na Tabela 2. As IVAS foram observadas em 304 casos (63\%) de IRAs analisados. Cinco dos
Características da população

Tabela 1 estudada

\begin{tabular}{|c|c|c|}
\hline Características & Total de crianças & IRA viral \\
\hline \multicolumn{3}{|l|}{ Sexo } \\
\hline $\begin{array}{l}\text { Masculino/ } \\
\text { feminino }\end{array}$ & $\begin{array}{c}251: 231 \\
(52 \%: 48 \%)\end{array}$ & $\begin{array}{c}88: 66 \\
(57,1 \%: 42,9 \%)\end{array}$ \\
\hline \multicolumn{3}{|l|}{ Local de coleta } \\
\hline $\begin{array}{c}\text { Emergência/ } \\
\text { enfermaria }\end{array}$ & $\begin{array}{c}360: 122 \\
(74,6 \%: 25,4 \%)\end{array}$ & $\begin{array}{c}105: 49 \\
(68,1 \%: 31,9 \%)\end{array}$ \\
\hline \multicolumn{3}{|l|}{ Idade (meses) } \\
\hline $0-6$ & $185(38,3 \%)$ & $61(39,6 \%)$ \\
\hline 7-12 & $143(29,6 \%)$ & $51(33,1 \%)$ \\
\hline 13-18 & $45(9,3 \%)$ & $16(10,3 \%)$ \\
\hline $19-24$ & $63(13 \%)$ & $14(9 \%)$ \\
\hline$>24$ & $46(9,5 \%)$ & $12(7,8 \%)$ \\
\hline
\end{tabular}

IRA = infecção respiratória aguda.

seis vírus mais associados às IRAs causaram mais casos de IVAS que IVAI. A análise estatística mostrou que houve uma predominância significativa dos casos de IVAI causados pelo $\operatorname{VSR}(p=0,001)$.

A distribuição dos casos de IRA entre os diferentes vírus pesquisados, tendo como base o local de atendimento e o diagnóstico, pode ser vista na Tabela 3. As IVAS virais foram observadas predominantemente em crianças da emergência $(69,8 \%)$, enquanto que as IVAl foram observadas predominantemente em crianças de enfermaria $(83,4 \%)$. Uma associação estatisticamente significativa foi observada entre a ocorrência de IVAS pelo VSR em pacientes de emergência e IVAI em pacientes de enfermaria

Vírus respiratórios identificados em casos de infecção respiratória aguda e diagnóstico clínico estabelecido em crianças atendidas no Centro Pediátrico Professor Hosannah de Tabela 2 Oliveira, da Universidade Federal da Bahia, no período de janeiro a dezembro de 1998

\begin{tabular}{lcccccccc}
\hline $\begin{array}{l}\text { Diagnóstico } \\
\text { clínico }\end{array}$ & $\begin{array}{c}\text { Total de } \\
\text { amostras }\end{array}$ & VSR & Ad & Flu A & Flu B & PF1 & PF3 & $\begin{array}{c}\text { Amostras } \\
\text { positivas }\end{array}$ \\
IVAS & 304 & 87 & 37 & 8 & 18 & 5 & 0 & 18 \\
& $(63 \%)$ & $(56,4 \%)$ & $(44 \%)$ & $(72,7 \%)$ & $(66,7 \%)$ & $(88,3 \%)$ & & $(72 \%)$ \\
IVAI & 178 & 68 & 47 & 3 & 9 & 1 & 1 & 7 \\
& $(37 \%)$ & $(38,2 \%)$ & $(56 \%)$ & $(27,3 \%)$ & $(33,4 \%)$ & $(12,7 \%)$ & $(100 \%)$ & $(28 \%)$ \\
Total & $\mathbf{4 8 2}$ & $\mathbf{1 5 4}$ & $\mathbf{8 4}$ & $\mathbf{1 1}$ & $\mathbf{2 7}$ & $\mathbf{6}$ & $\mathbf{1}$ & $\mathbf{2 5}$ \\
\hline
\end{tabular}

IVAS = infecções de vias aéreas superiores; IVAI = infecções de vias aéreas inferiores; VSR= vírus sincicial respiratório; $A d=$ adenovírus; Flu $A$ = influenza A; Flu $B=$ influenza $B ; P F 1$ = parainfluenza $1 ;$ PF3 = parainfluenza 3 . 
Distribuição dos casos de infecção respiratória aguda entre os três vírus mais prevalentes em casos de IRA do Centro Pediátrico Professor Hosannah de Oliveira, da Universidade Federal

Tabela 3 da Bahia, durante 0 ano de 1998, segundo o local de coleta e o diagnóstico

\begin{tabular}{lcccccc}
\hline Diagnóstico/ & VSR & VSR & Flu A & Flu A & PF3 & PF3 \\
Local & ENF & EM & ENF & EM & ENF & EM \\
IVAI & 26 & 21 & 5 & 6 & 7 & 2 \\
& $(86,7 \%)$ & $(39 \%)$ & $(45,4 \%)$ & $(64,6 \%)$ & $(77,7 \%)$ & $(22,8 \%)$ \\
IVAS & 4 & 33 & 1 & 15 & 2 & 14 \\
& $(13,3 \%)$ & $(61 \%)$ & $(6,3 \%)$ & $(93,7 \%)$ & $(12,5 \%)$ & $(87,5 \%)$ \\
Total & $\mathbf{3 0}$ & $\mathbf{5 4}$ & 6 & $\mathbf{6} 1 \%$ & $\mathbf{9}$ & 16 \\
& $(\mathbf{3 5 , 7} \%)$ & $(\mathbf{6 4 , 3} \%)$ & $\mathbf{( 2 2 , 2 \% )}$ & $\mathbf{( 7 7 , 8 \% )}$ & $\mathbf{( 3 6 \% )}$ & $\mathbf{( 6 4 \% )}$ \\
\hline
\end{tabular}

VSR = vírus sincicial respiratório; Flu $A=$ influenza $A ;$ Flu $B=$ influenza $B ; P F 3=$ parainfluenza 3; IVAS = infecção de vias aéreas superiores; IVAl = infecções de vias aéreas inferiores; $E M$ = emergência; $E N F$ = enfermaria.

$(p=0,001)$. As IVAS pelo influenza A foram associadas significativamente a pacientes atendidos na emergência $(p=0,002-$ Teste de Fisher). As IVAl pelo parainfluenza 3 foram associadas significativamente a pacientes de enfermaria ( $p=0,002$ - Teste de Fisher).

Com relação aos dados sociodemográficos, observouse que em $51,4 \%$ dos casos havia relato de IRA em outros membros da família. No caso das infecções virais, esta associação foi de $42,8 \%$. A ocorrência de IRAs virais foi maior em casas com mais de cinco pessoas do que naquelas com apenas três pessoas. A associação entre a presença de fumantes e a ocorrência de IRAs virais não se mostrou estatisticamente significativa, apesar de, entre os 154 casos de IRAs virais, 82 terem ocorrido em famílias com um ou mais fumantes.

\section{Discussão}

A prevalência de infecções respiratórias virais neste estudo foi de $31,9 \%$, o que está dentro de uma faixa de prevalência de infecções respiratórias virais, encontrada em alguns estudos brasileiros, que varia entre $18 \%$ e 54,6\% (1, $8,9,24,27,31,35-38,40)$. Esta ampla variação pode ser explicada tomando-se como base as diferentes metodologias empregadas no diagnóstico, as síndromes clínicas estudadas, a duração do estudo, a idade dos pacientes incluídos no estudo e o local de atendimento dos pacientes. Uma série de outros vírus, como o picornavírus (rinovírus e enterovírus), o vírus do sarampo e o herpesvírus, entre outros, que também causam quadros de infecções respiratórias, não foram pesquisados neste estudo. A utilização de métodos que também pesquisassem estes vírus poderia resultar em uma prevalência maior de IRAs virais.
$\mathrm{O}$ vírus mais prevalente nesse estudo, o VSR, tem sido apontado em diferentes estudos brasileiros como o agente mais freqüente de IRAs que resultam em atendimento médico $(27,31,35,37)$. Dois estudos sobre IRAs virais em cidades nordestinas destacam, neste mesmo aspecto, a importância dos rinovírus e dos enterovírus em outros locais de atendimento $(1,36)$. As IRAs virais em crianças de uma creche de Salvador foram mais freqüentemente causadas pelos rinovírus e pelos enterovírus, enquanto que o VSR foi responsável por apenas 2,5\% dos casos de IRA nessa população (36). Um estudo realizado em Fortaleza com crianças com IRA visitadas em seus domicílios apresentou rinovírus, parainfluenza e enterovírus como agentes mais prevalentes, não sendo identificado nenhum caso por VSR (1). Um estudo realizado na cidade do Rio de Janeiro, onde a maioria das amostras foi coletada de pacientes atendidos em hospitais, mostrou que os rinovírus e os enterovírus representavam $10,5 \%$ dos vírus identificados, sendo o VSR o agente mais prevalente (31).

Algumas características do período epidêmico de VSR em Salvador devem ser comentadas: a longa duração de sete meses e a associação do seu pico com o período de maior ocorrência de chuvas nesta cidade. A incidência aumentada de IRA nos meses mais chuvosos tem sido relatada em estudos de países de clima tropical $(7,17)$. Esta associação também já foi relatada em um estudo realizado em Belém e na região amazônica (22). Outros estudos têm mostrado um padrão diversificado de sazonalidade do VSR no Brasil. Em trabalhos realizados em algumas cidades da região Sudeste, o período epidêmico de VSR ocorre no primeiro semestre de cada ano, com uma pequena variação em sua extensão e no que se refere aos meses de pico destas infecções. Nas cidades do Rio de 
Janeiro e São Paulo, o período epidêmico de VSR começa no final de março ou início de abril, atinge o pico em maio e dura cerca de cinco meses $(24,27)$. Na cidade de Vitória, um estudo realizado durante treze meses consecutivos mostrou que infecções pelo VSR foram identificadas na maioria dos meses de estudo (com exceção de agosto e dezembro), com pico de ocorrência nos meses de fevereiro a abril (35). Relatos sobre IRAs virais na região Sul correlacionam o pico de ocorrência de VSR ao meses mais frios do ano (junho a agosto), um padrão que se mostra mais semelhante ao verificado em países do Cone Sul da América do Sul $(2,32,33,37,38)$.

Os vírus influenza, assim como o VSR, têm um padrão de sazonalidade em áreas geográficas específicas $(12,15$, 26). Neste estudo, um surto de influenza foi observado de setembro a novembro, e casos esporádicos foram observados de março a junho. Dados de alguns estudos brasileiros sugerem que os surtos de influenza podem ocorrer em qualquer estação do ano $(10,22,27)$. Na cidade de Fortaleza, os picos de influenza têm sido associados à estação de chuvas (1), o que não foi observado em Salvador durante o ano de 1998. Na cidade de Porto Alegre, a ocorrência de influenza foi relacionada ao período de inverno (37).

$O$ vírus parainfluenza tipo 3 foi identificado em casos de IRA em oito meses durante o período de estudo, mas sempre em baixa freqüência e sem qualquer associação com o período de chuvas, como havia sido observado em estudo realizado durante 29 meses na cidade de Fortaleza (1). O único caso de IRA causado pelo parainfluenza tipo 1 neste estudo aconteceu no pico de ocorrência das IRAs em uma criança com cardiopatia congênita que se internou com pneumonia e evoluiu para o óbito.

Nossos resultados apresentam o adenovírus como o quarto vírus em ordem de freqüência. $O$ atendimento predominante de crianças na emergência do CPPHO/UFBA pode ter gerado este resultado, uma vez que os estudos brasileiros e de outros países sul-americanos que mostram o adenovírus como o segundo vírus mais prevalente em caso de IRAs incluem exclusiva ou predominantemente crianças hospitalizadas (3, 20, 27, 34, 37). Assim como em outros locais, os adenovírus em Salvador não apresentaram um padrão de ocorrência em pico, mas numa baixa freqüência na maioria dos meses de estudo $(19,39)$.

As IRAs virais e aquelas de etiologia não-identificada foram associadas significativamente a crianças de até um ano de idade, o que está de acordo com a literatura (8, $13,14,27,29,35,37,40)$. O VSR e o parainfluenza 3 causaram infecções principalmente em crianças de até seis meses, enquanto que adenovírus e influenza A causaram infecções predominantemente em crianças entre seis e 12 meses de vida. O VSR foi o único vírus pesquisado a causar IRA em crianças até um mês de idade. Estas infecções foram diagnosticadas como IVAl em $80 \%$ dos casos e resultaram em internação em $84,6 \%$. Uma alta prevalência de IRA pelo VSR foi observada em crianças com menos de um mês de vida na cidade de Vitória (ES) (35). Um estudo que analisava a gravidade dos casos de IRA devido ao VSR mostrou que, dentro dessa faixa etária, os casos foram considerados moderados ou graves (8).

A predominância de casos de IVAS no nosso estudo pode estar relacionada ao elevado número de crianças atendidas na emergência. A maioria dos estudos que incluem apenas crianças hospitalizadas geralmente analisa apenas casos de IVAI e pode não refletir o comportamento real das infecções respiratórias na comunidade por selecionar casos de maior gravidade. Entre os vírus pesquisados nesse estudo somente o VSR causou mais casos de IVAI. A predominância das IVAI foi observada em crianças no seu primeiro ano de vida, sendo associadas em sua maioria $(77,9 \%)$ aos três vírus mais prevalentes.

Assim como neste estudo, outros estudos brasileiros têm associado as IRAs virais a uma baixa mortalidade (8, $24,27,35)$. Devemos considerar, no entanto, que a evolução completa das IRAs virais em crianças atendidas no CPPHO/UFBA foi acompanhada apenas nos pacientes de enfermaria, onde apenas um caso resultou em óbito. Os casos atendidos na emergência não eram acompanhados em sua evolução completa, uma vez que a maioria dos pacientes retornava para sua casa logo após o atendimento. Deste modo, se algum óbito ocorreu nesse grupo de pacientes, o mesmo não pôde ser registrado. A elevada taxa de mortalidade infantil em casos de pneumonia viral, segundo estudos realizados em países em desenvolvimento, está consideravelmente associada ao vírus do sarampo, que não foi pesquisado por nós $(18,21,30)$.

A confirmação de uma maior ocorrência de IRAs virais no primeiro semestre do ano, em Salvador, através de estudos longitudinais, poderá ser útil na estruturação dos diferentes níveis de atendimento de saúde para os períodos de pico destas infecções. A utilização de métodos de diagnóstico rápido das IRAs virais poderá ser útil na redução do número e do período de hospitalizações, na racionalização do uso de antibióticos e, finalmente, na indicação de uma terapia antiviral para casos específicos. 


\section{Referências}

1.A rruda, E.N .et al.A cute respiratory viral infections in ambulatory children of urban N ortheast, Brazil. J Infect Dis, 164: 2528,1991.

2.Avendaño, L.F.; Larranaga, C.\& Palomino M.A.Community and hospital-acquired respiratory syncytial virus infections in Chile. Pediatric Infectious Diseases Journal, 10:564-8, 1991.

3. A vila, M. et al. Isolation and identification of viral agents in A rgentinean children with acute lower respiratory tract infection. Rev Infect Dis, 12(suppl. 8): S 974-81,1990.

4. Berman, S. et al. A cute lower respiratory tract illnesses in Cali, Colombia: a two years' ambulatory study. Pediatrics, 71:210-8,1983.

5. Berman, S. Epidemiology of acute respiratory infections in children in developing co untries. Rev Infect Dis, 12 (suppl.): S454-62, 1991.

6. Campbell, $\mathrm{H}$.A cute respiratory infections are main killer of under 5s. Br Med J, 304: 335, 1993.

7. Cherian, $T$ et al. Bronchiolitis in tropical South India. Am J Dis Child, 144(9): 1026-30, 1990.

8. Cintra, O .A.L. Ocorrência e gravidade do vírus sincicial respiratório, grupos A e B, em crianças de 0 a 24 meses de idade atendidas em pronto-socorro de pediatria na cidade de Ribeirão Preto, São Paulo. 1997. D issertação (mestrado). Faculdade de Medicina de Ribeirão Preto, Universidade de São Paulo, Ribeirão Preto.

9. Cintra, O .A.L et al. O ccurrence and severity of infections caused by subgro ups $A$ and $B$ respiratory syncytial virus in children in Southeast Brazil. J M ed Virol, 65(2): 408-12, 2001.

10. Dos Santos, D.E.M.; C ardias, C .A.S. \& Mello, W .A. Inquérito soro epidemioló gico para o vírus influenza em Belém, Pará, Brasil, 1992-1993. Cad Saúde Publ, 13(1): 119-25, 1997.

11. Gardner, P.S \& McQ uillin, J. Rapid virus diagnosis. Aplication of immunofluorescence. 2 ed. Londres: Butterworth, 1980.

12. G hendon,Y. Influenza surveillance. BullW H 0,69:509-15, 1991.

13. G lezen, W .P. et al. Risk of respiratory syncytial virus infection for infants from low-inco me families in relationship to age, sex, ethnic group, and maternal antibody level. Pediatrics, 98(5); 708-15, 1981.

14. Hall, C.B. et al. N eonatal respiratory syncytial virus infection. N Engl J Med, 300(8): 393-6, 1979.

15. Hayden,F.G \& Palese,P.Influenza virus. In: Richman,D .D ;W hitley, R.J. \& Hayden F.G. (eds.) Clinical Virology.1 ed. N ew York: Churchill Livingstone,1997. p. 919-20.

16. Hazlett,D.T.G. et al.Viral etio logy of acute respiratory infections in children in N airobi, Kenya. Am JTrp M ed Hyg, 39:632-40, 1988.

17. H ierholzer, J.C . et al. Subgrouping of respiratory syncytial virus strains from A ustralia and Papua N ew Guinea by biological and antigenic characteristics. Arch Virol, 136: 133-47, 1994.

18. Jain, A. et al. An Indian hospital study of viral causes of acute respiratory infections in children. J M ed M icrobiol, 35: 21923, 1991.

19. John,T.J. et al.Etio lo gy of acute respiratory infections in children in tropical southern India. Rev Infect Dis, 13(suppl. 6): 463-9,1991.
20. Larrañaga, C . et al. A denovirus surveillance on children hospitalized for acute respiratory infections in Chile (19881996). J Medical Virology, 60: 342-6, 2000.

21. Markowitz, L.E. \& N eiburg, P. The burden of acute respiratory infection due to measles in develo ping countries and the potential impact of measles vaccine. Rev Infect Dis, 13: S555, 1991.

22. Mello, W .A \& Pinheiro, E.P. Viroses respiratórias. In: Instituto Evandro Chagas: 50 anos de contribuição às ciências biológicas e à medicina tropical. Belém, MS: Fundação de Serviços de Saúde Pública, 1986. p. 473-81.

23. Ministério da Saúde do Brasil. Sistema de informação sobre mortalidade no perío do de 1979 a 1993. Dados de declarações de óbitos. Fundação N acional de Saúde, Brasília, 1995.

24. Miyao, C .R. et al. Infecções virais em crianças internadas por doença aguda do trato respiratório inferior. Jornal de Pediatria, 75(5): 334-44, 1999.

25. Monto, A.S.Viral respiratory infections in the community: epidemio logy, agents, and interventions. Am J Med, 99(6B): 24S-7S, 1995.

26. Monto, A.S. \& Sullivan, K.M. A cute respiratory illness in the community: Frequency of illness and the agent involved. Epidemiol Infect, 110: 145, 1993.

27. N ascimento, J.P. et al. Longitudinal study of acute respiratory diseases in Rio de Janeiro: occurrence of respiratory viruses during four consecutive years. Rev Inst Med Trop S. Paulo, 33(4): 287-96,1991.

28. O rganización Mundial de la Salud /O rganización Panamericana de la Salud. N eumonia en los niños: estrategias para hacer frente al desafio. Informe de la primera reunión consultiva internacional sobre el control de las infecciones respiratorias agudas RCICIRA.W ashington, DC, 1993. 101p.

29. Parrot, R.H . et al. Epidemiology of respiratory syncytial virus infection in W ashington D.C. II: infection and disease with respect to age, immunologic status, race and sex. Am J Epidemiol, 98: 289-300, 1973.

30. Pio, A; Leowski, J. \& Luelmo, F. Epidemiological magnitude of the problem of acute respiratory infections in developing countries. Bull Int Against Tuber, 58: 199-208,1983.

31. Portes, S.A.R et al. Enterovirus isolated from patients with acute respiratory infections during seven years in Rio de Janeiro (1985-1991). Rev Inst Med Top S. Paulo, 40(6): 337-42, 1998.

32. Russi,J.C .et al.A ntigenic characterization of respiratory syncytial virus associated with acute respiratory infection in Uruguayan children from 1985 to 1987.J Clin Microbiol, 27: 1464-6, 1992

33. Salomón, H.E. et al. Clinical and epidemiological aspects of respiratory syncytial virus antigenic variants in A rgentinean children.J Infect Dis, 163: 1167, 1991.

34. Savy, V. et al. Evaluación etiológica y clínica de infecciones respiratorias agudas bajas en una población infantil. M edicina (Buenos Aires), 56: 227-31, 1996. 
35. Silva, R.E.C.F. Contribuição ao estudo epidemiológico do vírus sincicial respirtório na região metropolitana deVitória, ES, Brasil. 1999. Dissertação (mestrado). Universidade Federal do Espírito Santo,Vitória.

36. So uza, L.S.F. Infecções respiratórias virais em crianças de uma creche. 1999.Tese (doutorado). Faculdade de Medicina,U niversidade Federal da Bahia, Salvador.

37. Straliotto, S.M. Prevalência de vírus respiratórios em pacientes pediátricos. 1995. Dissertação (mestrado). Fundação Faculdade Federal de Ciências Médicas e Irmandade da Santa C asa de Misericórdia de Porto A legre, Por to A legre.

38. Straliotto, S.M.; N estor, S.M. \& Siqueira, M.M. Respiratory syncytial virus groups $A$ and $B$ in Porto Alegre, Brazil, from
1990 to 1995 and 1998. Mem Inst Oswaldo Cruz, 96(2): 155-8, 2001.

39. Sung, R.Y.T. et al. Epidemiology and aetiology of acute bronchiolitis in Hong Kong infants. Epidemiol Infect, 108: 147-54,1992.

40. Sutmoller, F. et al. Etiology of acute respiratory tract infections among children in a combined community and hospital study in Rio de Janeiro. Clin Infect Dis, 20: 854-60, 1995.

41.W alsh E.E. \& H all, C .B. Respiratory syncytial virus. In: D iagnosis procedures for viral, rickettsial and chlamydial infections. In: Schimidt, N .J. \& Emmons, R.W . (eds) 6 ed.W ashington: A merican Public Health Association, 1989, p. 693-712. 